\title{
Striatonigral Degeneration
}

National Cancer Institute

\section{Source}

National Cancer Institute. Striatonigral Degeneration. NCI Thesaurus. Code C125695.

A progressive neurodegenerative disorder caused by a disruption in the connection between the striatum and the substantia nigra. It is a type of multiple system atrophy (MSA). Signs and symptoms include rigidity, instability, impaired speech, and slow movements. 